\title{
MATERNAL LITERACY AND MALNUTRITION IN CHILDREN: A COMPARATIVE STUDY
}

\author{
SYED RAZI HAIDER ZAIDI ${ }^{1}$, JAVED IQBAL $^{2}$, TAHIR MAHMUD ${ }^{3}$, NEELAM RAHEEL $^{4}$, AROOJ FATIMA $^{3}$ \\ ${ }^{1}$ Department of Community Medicine, Postgraduate Medical Institute/Ameer ud Din Medical College/Lahore, \\ ${ }^{2}$ Department of Cardiac Surgery, Rawalpindi Institute of Cardiology, Rawalpindi, ${ }^{3}$ Institute of Public Health, Lahore \\ ${ }^{4}$ Rashid Lateef Medical College, Lahore.
}

\begin{abstract}
:
Objective: Nutritional status is an important aspect of child's health profile and affects child's development and growth. This study aimed at exploring relationship between maternal literacy and malnutrition in children under-five years old. Methods: Two groups were made comprising of mothers, according to the nutritional status of their under-five children presenting in free clinic in Ali Raza Abad Lahore with URTI.

Results: Significant difference was found in literacy level in two groups; with 38\% illiteracy amongst mothers with malnourished children as compared to $14 \%$ amongst women with children not suffering from malnutrition and $\mathrm{p}$ value at 0.0062. More mothers of children suffering from malnutrition were found illiterate as compared to mother of well-nourished children. Conclusion: As illiteracy affected children nutrition it is recommended that illiterate women may be targeted for health education on short term basis and education be made mandatory for long term solution to this problem.
\end{abstract}

Keywords: malnutrition, maternal literacy, under-five children

How to cite this article: Zaidi SRH, Iqbal J, Mahmud T, Raheel N, Fatima A. Maternal literacy and malnutrition in children: A comparative study. Pak Postgrad Med J 2020;31(1): 29-31

This is an Open Access article distributed under the terms of the Creative Commons Attribution License (http://creativecommons.org/licenses/by/3.0), which permits unrestricted use, distribution, and reproduction in any medium, provided the original work is properly cited.

DOI: HTTPS//DOI.ORG/10.51642/ppmj. v31i01.128

Correspondence to: Razi Haider Zaidi, Assistant Professor, Department of Community Medicine, Postgraduate Medical Institute/Ameer-ud-Din Medical College/ Lahore General Hospital, Lahore, Pakistan.

E-mail: haniravian@gmail.com

\section{INTRODUCTION}

While malnutrition remains the biggest hurdle in improving children health globally especially third world countries and affects normal development, hence increasing morbidity and mortality in this vulnerable group. Nearly half of all deaths in children under five are attributable to under nutrition, translating into the loss of about 3 million young lives a year. ${ }^{1}$ In 2017, in under 5 year children globally. 50.5 million were wasted and 150.8 million were stunted. While stunting is less than minus 2 SD for height for age and wasting is less than minus $2 \mathrm{SD}$ for weigth for height. ${ }^{2}$ Infections e.g diarrhea in the setting of malnutrition lead to more complications, deaths and delay recovery. ${ }^{3}$

In KPK, district Nowshera, Ali et al, found that $12.5 \%$ children were stunted, $15 \%$ were underweight, and $7 \%$ were wasted. ${ }^{4}$ Another study from KPK, Afridi accounted that $14 \%$ children are underweight, $8 \%$ were underweight and stunned in Swat. ${ }^{5}$ In a study from Quetta, Baluchistan it was reported that one out of two $(48 \%)$ children were stunned and $10 \%$ were wasted. ${ }^{6}$ In another study Ansari highlighted that $22 \%$ children were stunned, $10 \%$ were wasted, and $24 \%$ were underweight in urban areas of Pakistan. ${ }^{7}$ Similar finding was also presented by the Batool that the prevalence of stunting was $46 \%$ and underweight was $25 \%$ and $18 \%$ was under weight. ${ }^{8}$ In Sindh province, the situation of children in term of stunting, wasting, and underweight is alarming according to different studies. Nisar reported that $61 \%$ of children were stunned, 54\% were underweight, and $47 \%$ were wasted in rural Sindh. ${ }^{9}$ Similar findings were observed by Shah, who found that $26 \%$ children were 
wasted, $55 \%$ were stunned, and $15 \%$ were both wasted and stunned in hospitalized children. ${ }^{10}$

Asim et al in 2018 conducted a meta-analysis and concluded that Early marriages, large family size, high fertility rates with a lack of birth spacing, low income, and the lack of breastfeeding and exclusive breastfeeding were found to be major determinants of child malnutrition. ${ }^{11}$ Ickes et al observed that low maternal literacy was associated with poor infant and child feeding practices and malnutrition in children. ${ }^{12}$ Khattak et al also found that paternal and maternal education levels were significantly associated with children nutritional status. 13 Children malnutrition is a key subject if dealt with properly can improve health parameters in children. This study aimed at exploring relationship between maternal literacy and malnutrition in children under-five years to identify high risk strata so that strategies could be focused to bring behavior changes to improve children malnutrition.

\section{METHODS}

Hundred mothers were interviewed presenting in family health clinic in Ali Raza Abad, Lahore with Upper respiratory tract infections of recent origins (less than 3day duration of illness), were divided into two groups based on nutrition status of their child into well-nourished and malnourish group if the child weight for age of height for age was less than $3^{\text {rd }}$ percentile as per WHO growth monitoring chart. Questionaries were filled after taking consent. Literacy was assessed if woman could read consent form and write that she gives consent for the study in Urdu.

\section{RESULTS}

Group A consisted of mothers whose children had malnutrition according to the criteria specified above. Mean age of the women in Group A was 34+/- 6 years of age. Mean family income was 29000 +/- 11000rs per month. They all lived in the urban areas. $21(42 \%)$ lived on rent. 31(62\%) were living in unitary families while $19(38 \%)$ lived in combined families. Mean number of children were 3.3+/- 1.2. 33(66\%) women were housewives while $7(14 \%)$ worked in schools and $4(8 \%)$ worked in factories, 6(12\%) were doing in home-based business. 31(62\%) mothers could read the consent form and had given written consent showing literacy while $19(38 \%)$ could not read consent and given written consent

Group B consisted of mothers whose children were not suffering from malnutrition according to the criteria specified above. Mean age of the women of Group B was $35+/-7$ years of age. Mean family income was 35500 $+/-9000$ rs per month. They all lived in the urban areas. 17 (34\%) lived on rent. 22(44\%) were living in unitary families while $28(56 \%)$ lived in combined families. Mean number of children were $3+/-1.5$. 36(72\%) women were housewives while $6(12 \%) \%$ worked in schools and $2(4 \%)$ worked in factories, $6(3 \%)$ were doing in homebased business. $43(87.5 \%)$ women read the consent form and wrote clearly that they give consent showing that they were literate while 7 (14\%) women could not read the form.

Table:1 Sociodemographic characteristics

\begin{tabular}{llcc}
\hline Socio demographic features & $\begin{array}{c}\text { Group A } \\
\mathrm{n}=50\end{array}$ & $\begin{array}{c}\text { Group B } \\
\mathrm{n}=50\end{array}$ \\
\hline Mean age & $\begin{array}{c}36+/-6 y e a r \\
29000+/-\end{array}$ & $\begin{array}{c}37+-7 \text { years } \\
35500+/-\end{array}$ \\
Mean income & $11000 \mathrm{rs}$ & $9000 \mathrm{rs}$ \\
Mean number of children & $3.3+/-1.2$ & $3+/-1.5$ \\
Resident of & urban & $50(100 \%)$ & $50(100 \%)$ \\
area & rural & $0(0 \%)$ & $0(0 \%)$ \\
house & own & $29(58 \%)$ & $33(66 \%)$ \\
& rented & $21(42 \%)$ & $17(34 \%)$ \\
Family type & unitary & $31(62 \%)$ & $22(44 \%)$ \\
& combine & $19(38 \%)$ & $28(56 \%)$ \\
Nature of & House wife & $33(66 \%)$ & $36(72 \%)$ \\
work & School teachers & $7(14 \%)$ & $6(12 \%)$ \\
& Factory worker & $4(8 \%)$ & $2(4 \%)$ \\
& House based & $6(12 \%)$ & $6(12 \%)$ \\
\hline & business & & \\
\hline
\end{tabular}

Chi square test of applied and difference between literacy amongst mother with children suffering from malnutrition as compared to the ones not suffering was found significant with pat 0.0062 . Table 2

Table 2: Maternal illitracy and malunutrition in children $\mathrm{n}=100$

\begin{tabular}{rccc}
\hline & $\begin{array}{c}\text { Mother with } \\
\text { malnourished } \\
\text { children }\end{array}$ & $\begin{array}{c}\text { Mother with } \\
\text { well-nourished } \\
\text { children }\end{array}$ & P value \\
\hline Illiteracy Present & $19(38 \%)$ & $6(12 \%)$ & .0062 \\
Absent & $31(62 \%)$ & $44(88 \%)$ & \\
\hline
\end{tabular}

\section{DISCUSSION}

Nutritional status is an important aspect of children health profile and directly and indirectly affects child's development and growth. If not, adequate it complicates many diseases and affects resistance to diseases and vulnerability to succumb to greater morbidity and mortality. Asim et al in his meta-analysis identified many social factors associated with malnutrition in children. ${ }^{11}$ This study shows strong association between maternal illiteracy and malnutrition as significantly larger proportion of illiteracy was observed in mother of 
malnourished children. The observation is interesting in the fact that despite the advent of nonconventional health educational tools in the form of media and Tv where minimal literacy is required to gain health education passively, malnutrition showed association with maternal literacy which clearly shows that despite health education through Tv and media broadcasts, education does have a role in prevention malnutrition in the children. Ickes et al had similar finding where maternal literacy showed strong association with poor infant and child feeding practices and malnutrition. ${ }^{12}$ Results of this study are also in consensus with finding of Khattak et al who also observed strong association between maternal literacy and child's nutritional status. ${ }^{13}$

\section{CONCLUSION}

While stake holders are committed to betterment of health especially of vulnerable strata, need of the hour is to take wholesome actions in order to improve child health of the community. Literate mothers have shown to have well nourished children compared to illiterate mothers. Thus a more robust health education strategy for the illiterate mothers through social and health workers is recommended in the short term and a more wholesome approach that is mandatory education is recommended on long term basis.

\section{ETHICAL APPROVAL}

The study was approved from Institutional Review Board of Postgraduate Medical Institute/Ameer ud Din Medical College/Lahore General Hospital, Lahore, Pakistan, vide reference No. 00-40-21, dated March 01, 2021.

\section{REFERENCES}

1. United Nations Children's Fund, Progress for Children. Global Nutrition Report 2017:Nourishing the SDGs. November 2017 .Reprinted with the permission of UNICEF.

2. UNICEF. Nutrition-Definition of the Indicators, UNICEF, The State of the world's children, Oxford University Press, New York: 2004, p. 109

3. UNICEF. Malnutrition - Silent emergency, UNICEF, The State of the world's children, Oxford University Press, New York: 1998, pp. 9-11.

4. Ali W., Ayub A., Hussain H. Prevalence and associated risk factors of under nutrition among children aged 6 to 59 months in internally displaced persons of jalozai camp, District Nowshera, Khyber Pakhtunkhwa. J. Ayub Med. Coll. Abbottabad. 2015;27:556-559.
5. Afridi M.F., Khushdil A., Riaz S., Ehsan A. Nutritional status of pre-school children-A cross-sectional study in Mingora, Swat. J. Postgrad. Med. Inst. 2014;28:314-328.

6. Achakzai P., Khan R. Nutritional status and associated factors among children less than five years of age in tehsil Zarghoon town, District Quetta, Baluchistan. J. Ayub Med. Coll. Abbottabad. 2016;28:146-151.

7. Baig-Ansari N., Rahbar M.H., Bhutta Z.A., Badruddin S.H. Child's gender and household food insecurity are associated with stunting among young Pakistani children residing in urban squatter settlements. Food Nutr. Bull. 2006;27:114-127. doi: 10.1177/ 156482650602700203.

8. Batool S., Shaheen A., Rehman R. To Assess the Nutritional Status of Primary School Children in an Urban School of Faisalabad. Pak. J. Med. Health Sci. A. 2012;4:160.

9. Nisar Y.B., Aurangzeb B., Hazir T. Nutritional Status of Hospitalized Children with Nutritional Anaemia: A Cross Sectional Study. Ann. Pak. Inst. Med. Sci. 2013;9:122-125.

10. Shah S.M., Selwyn B.J., Luby S., Merchant A., Bano R. Prevalence and correlates of stunting among children in rural Pakistan. Pediatr. Int. 2003;45:49-53. doi: 10.1046/j.1442-200X.2003.01652.x.

11. Asim M, Yasir Nawaz Y.Child Malnutrition in Pakistan: Evidence from Literaturev. PMC. 5(5); 2018 May

12. Ickes SB, Hurst TE, Flax VL. Maternal Literacy, Facility Birth, and Education Are Positively Associated with Better Infant and Young Child Feeding Practices and Nutritional Status among Ugandan Children. J Nutr. 2015 Nov; 145(11): 2578-2586.

13. Khattak UK, Iqbal SP, Ghazanfar H. The role of parents' literacy in malnutrition of Children Under the Age of Five Years in a Semi-Urban community of Pakistan: a case-control study. Cureus. 2017 Jun; 9(6): e1316.

\section{AUTHORS' CONTRIBUTION:}

SRHZ: Study design, Manuscript writing

JI: Data analysis, drafting

TM: Literature search, data interpretation, drafting

NR, AF: Data Analysis, Data Collection 